\title{
Analysis \& Implementation of Personalisation Parameters in the Development of Computer-Based Adaptive Learning Environment
}

\author{
Humam K. Majeed Al-Chalabi, Aqeel M. Ali. Hussein \\ Automatics Computers and Electronics Faculty, University of Craiova, Craiova, Romania
}

\begin{abstract}
The paper was aimed to identify the ways and to develop the model for the implementation personalised parameter for adaptive learning in the current E-learning environment. The study is qualitative in nature and relied on previous literature. The results highlighted that the personalised parameters which should be considered before the beginning of the course learning process include the level of learner's knowledge, goals of the leaners, preferences of the language, style of learning, information seeking task, bandwidth, location, and previous level of knowledge. The study also pointed out learning needs, motivation levels, working memory capacity, intelligence, cognitive style, satisfaction, delight, and self-efficacy, the need for help, selfregulated learning, and ongoing interactions, waiting for feedback, ongoing progress, and navigation preference as the parameters for considering in ongoing sessions. The study formulated an implementation design comprising a combination of CBR and RBR strategies. The design is further categorised into standalone and coupling strategies, while the coupling strategy further includes a combination of embedded, co-processing and sequential processing strategies.
\end{abstract}

Keywords - Software agents, E-learning systems, Adaptive learning, E-learning environment, Personalisation parameters, Learner model

DOI: $10.18421 /$ SAR31-01

https://doi.org/10.18421//SAR31-01

Corresponding author: Humam K.Majeed Al-Chalabi, University of Craiova, Craiova, Romania

Email: hemoomajeed@gmail.com

Received: 27 December 2019.

Revised: 20 February 2020.

Accepted: 27 February 2020.

Published: 30 March 2020.

(c))BY-NC-ND 2020 Humam K.Majeed Al-Chalabi \& Aqeel M.Ali.Hussein; published by UIKTEN. This work is licensed under the Creative Commons Attribution-

NonCommercial-NoDerivs 3.0 License.

The article is published with Open Access at www.sarjournal.com

\section{Introduction}

The personalisation parameters for computer-based learning basically aim at establishing such a learning environment and learning experiences that support and promote learner's skills or knowledge acquisition. These adaptive learning environment and experience involve actions, for example, directing individuals towards accurate information, giving feedback, monitoring the performance of individuals, etc. However, the problems related to the personalisation in the computer-based systems has become a very significant research topic in recent years. With the evolution of web-based systems of learning, content access has become possible for a large amount of learning communities across the world, who due to different circumstances are not able to receive a formal education [1]. At the same time, this large access to learning content has established certain challenges with regards to giving appropriate learning environment and experience to different students, as the systems of web-based learning do not usually implement content that can suit the needs of individual learners. However, with the rise of personalised computer-based learning, the interest, success, and comprehension of the learners will significantly increase [2]. The implementation of personalised learning parameters can significantly help in understanding and adapting the given content in accordance with the needs and requirements of the learners, and it is considered as one of the important channels through which the efficiency and acceptance of the E-learning will be significantly increased by the students [3]. Even though the combination of education and technology has given rise to distinctive, sophisticated, and renewed approaches to computer-based learning, there are still certain limitations associated with adaptive Elearning systems. These limits can also occur while defining the synergy between the learner and technological learning systems, and to the extent to which the learners are required to adopt the 
prevailing technology [4] . However, this document will analyse different personalisation parameter, and we will discuss how the parameters can be successfully implemented in the adaptive computerbased systems of learning.

\section{A. Background}

The personalised way of learning basically focuses upon providing an effective, customised, and efficient path of learning so that each and every student can engage in the learning process. The personalisation or adaptive parameter are based on various scenarios of E-learning systems. These parameters reflect the divergent needs and characteristics of each learner [5]. A number of previous research elaborates that the individual learning approach is quite superior to the traditional uniform approach which mainly focuses upon singular teaching methods for all learners. However, individual tutoring of humans increases the performance of learning as compared to the traditional teaching methods. Moreover, any type of content can be called adaptive if it supports various learning abilities and needs of the learners [6].

The increase in the growth of E-learning technologies has led to the evolution of adaptive learning experience. The recent technological advancement and the implementation of these technologies in the design of the learning content have resulted in individualization practices in which personalised learning content is provided simultaneously to a number of learners across the world coming from different backgrounds [7]. Adaptive E-learning environment enables a learner to choose the difficulty level according to his or her need for a specific learning course. Moreover, through adaptive computer-based learning, the learners will be able to study the learning content in accordance with their specific learning style, level of knowledge, state of mind. These adaptive systems basically adapt the individual's behavior through the process of acquisition of user model, and different applications that analyse the requirements of the user including the various form of decision-making, inference, and learning practices [8].

\section{B. Aim and Objectives}

The personalized parameters usually relate to such advanced systems that can automatically adapt to the learning behavior of the students. However, a system cannot be said to be adaptive if it is not responsive and flexible enough to suit the needs of learners. Thus, this gives rise to the fact that which feature or component of the E-learning system should be made adaptive in order to meet the requirements of the students [9]. Therefore, the main objective of this research work is to analyse such personalised parameters that could actually help the learners in learning various contents.

In recent years, there are a number of adaptive computer-based learning systems developed that utilises various personalisation parameters while keeping in mind the needs of the learners [10]. Thus, considering these adaptive learning practices this research work aims to provide a thorough discussion on how these personalized parameters can be implemented in computer-based learning systems.

\section{Research Question}

In order to meet the aims and objective of the research work, it will be quite important to examine the answers of the following question;

How the personalised parameter for adaptive learning can be implemented in the current E-learning environment?

\section{Literature Review}

This section will provide a thorough review of the literature about different personalized parameters in the adaptive E-learning systems. However, these personalised parameters can be divided into two types (1) the parameters that should be implemented before the beginning of the course, and (2) the parameters that should be implemented during the course learning process.

The personalised parameters that should be considered before the beginning of the course learning process include the level of learner's knowledge, goals of the leaners, preferences of the language, style of learning, information seeking task, bandwidth, location, and previous level of knowledge.

It is quite crucial for the adaptive E-learning technologies to take into account the level of learner's knowledge before beginning the coursework. This basically will help the learner to choose the level of difficulty of the coursework in accordance with his or her personal requirements. This specific personalised learning parameter will analyse the background of the learner, which will eventually help in communicating the learning content with the learner in the later stages [11]. Similarly, the goals of the learners should be set and analysed by the adaptive systems before the beginning of the learning process, in order to ensure that the set goals are met effectively and efficiently. Moreover, by identifying the learning goals, the Elearning system developers will be able to analyse and plan the course of learning, and it will also help them in communicating the materials of learning that 
could satisfy the goals of the learners [12]. Meanwhile, the language preferences also prevails as well to improve the learning experience of a learner. The main point of importance is that the learner has to be able to understand the concepts and information shared, which will be maximum due to higher level of familiarisation with the language [13]. Differences in language will work as a language barrier which will serve as a limiting factor of the learning process. Likewise, the learning abilities and cognitive abilities to learn also differ from person to the person, working as a parameter as a personalisation factor [14]. It calls for the personalisation of the learning experience regarding the individual for increasing linearity among the learning experience and the ability to learn. Information seeking tasks and prior experience of the individual impact his exposure to the learning process, which can also impact the upcoming learning session. Therefore, it is important for the learners and teachers to establish a personalised learning environment for increasing the effectiveness of the learning process. Bandwidths are also noted as an influencer of the learning experience of a person, which have to be reviewed as well for incorporating comprehensiveness in the learning experience of individuals. Differences between the bandwidth of the individuals and the learning environment may impact the performance of the learners seriously [15]. The geographical origin and current location of the individual may also work as personalisation factors asking for the customisation of the learning experiences. For instance, the current location of the individual may require to offer distant learning options or multimedia contents for improving the experience of the learners. Moreover, it is also important to consider that the current learning activity is often linked with the previous level of knowledge as introducing a highly qualified person in basic learning sessions may result in a higher level of frustration for the person. On the other hand, introducing advanced concepts may also be troublesome to understand for a person with no prior knowledge of the basic concepts [16]. The parameters discussed are some of the parameters which are to be considered at the entry-level for identifying the prior level of knowledge, and understanding as it can help to improve the quality and effectiveness of current learning sessions using suitable personalisation parameters.

Personalisation parameters are not confined to the prior experiences and characteristics of a person, and rather these parameters may also be relevant during the ongoing learning processes as well. For instance, assessing the individual needs of a learner for the learning process may also be helpful for the academic administration for facilitating the personalisation of learning environment [17].
Intrinsic factors, a part of an individual's personality, may also guide the personalisation of learning experience as some of the individuals may be more motivated for learning as compared to the others [4]. Still, the learners may also possess different levels of intelligence impacting the quality and effectiveness of learning experience and teaching methods. It has to be relevant to correlate the working memory of an individual with his level of intelligence as a composite personalisation factor for developing suitable adjustments. The rationale for the consideration of working memory and level of intelligence as parameters of individual personalisation is based on the differences in the cognitive abilities of a person that can impact the quality of learning even after the exposure of standardised learning environment [18]. Likewise, it is also important to consider that the feeling of an individual and perception of an individual may also be based on his personal intrinsic factors impacting the quality of the learning experiences. Internal satisfaction and delight of person may be, therefore, some of the relevant factors which can be considered as individual personalisation parameters [19]. Moreover, the ability to manage the things personally may also create a difference in the learning experiences of individual as some of the individual may possess higher levels of self-efficacy helping them improve the quality of their learning experiences, while the others may feel themselves challenged due to lower self-efficacy [19]. Meanwhile, the individuals may also possess different requirements for external supports which have to be based on some of the other factors as well. The need for help may require immediate attention of the administration for improving the learning experience of the people, which might not be fulfilled otherwise. The main point of consideration, here, is that the need for help must be considered as a personalisation parameter as well. The ability of a person to identify the priorities and to carry out the functions without external pressures or motives are also quite relevant concepts that have to be maintained throughout the process for increasing the linearity in the learning experiences. These differences may result in the categorisation of learners on the basis of their ability to regulate themselves requiring the academic administration in order to consider self-regulated learning as a personalised parameter. Ongoing interactions of a person with its environment and other individuals may also require the company to develop a better understanding of the learning abilities of a person. Attentiveness and participation of an individual in the learning process may also differ from person to person indicating differences in the level of interactions he makes during the learning process. 
For instance, some of the learners find it quite comfortable for them to ask questions for resolving ambiguities, while others may feel shy or confused in doing so creating differences in the quality of learning [20]. Waiting for feedback may also indicate the learning abilities and practices of an individual by pointing out his dependence on other factors. It may not be quite unique to witness an individual who continues to wait for the feedbacks for making necessary corrections. Still, another individual may ask for ongoing feedbacks and may also continue to explore his mistakes personally. These reliance factors clearly guides the level of changes required by an individual for using waiting/desperation of feedback as a parameter for improving the quality of the learning process due to increased personalisation. In the case of computer learning or e-learning, the individuals may possess different navigation skills and abilities that continue to impact their learning experiences seriously [21]. The main point of emphasis, here, is that the individual students may find it difficult for themselves to locate and identify the relevant learning materials and sources due to inability to categorise the learning material on the basis of their relative importance. Therefore, differences in navigation skills and abilities of individuals can impact the quality of computerlearning pointing out navigation skills as a personalisation parameter [22]. Besides all of the mentioned factors, the ongoing progress of individuals also points out the effectiveness of the learning arrangements for each of the individual in quite a systematic way. By reviewing the score-card and feedback of the teachers, one might be able to identify the ongoing progress of the individual.

The literature presented above highlighted that the individual personalisation parameters can be divided into two categories; parameters for consideration prior to the start of the learning process and parameters for consideration during the ongoing process. The literature pointed out that the personalised parameters that should be considered before the beginning of the course learning process include the level of learner's knowledge, goals of the leaners, preferences of the language, style of learning, information seeking task, bandwidth, location, and previous level of knowledge. The literature also highlighted that learning needs, motivation levels, working memory capacity, intelligence, cognitive style, satisfaction, delight, and self-efficacy, the need for help, self-regulated learning, and ongoing interactions, waiting for feedback, ongoing progress and navigation preference may be considered as the ongoing personalisation factors.

\section{Discussion}

This section will provide a comprehensive discussion depending upon the literature review, in the previous section, about different personalized parameters in the adaptive E-learning systems. The chapter will also provide an insight into opportunities and challenges attached to the implementation of these personalised parameters. The parameters identified will be discussed on the basis of their relative importance and effectiveness. The parameters identified in the literature basically deal with the cognitive abilities and the components of an external learning environment. Using standardized techniques for all of the people may not be equally suitable for all of the learners, which was highlighted by the literature as well requiring the needs for the personalisation of the learning settings for the individuals. The two categories identified in the literature may require categorical treatment as well.

\section{A. Implementing personalisation parameters at admission-level}

The personalised parameters identified in the literature survey above require a combination of rulebased; input by learner, rule-based; agent-based and case-based reasoning approach for making it quite an applicable approach for promoting and facilitating the implementation of personalised parameters in the learning process. The use of artificially intelligent technologies may be helpful for further improving the quality and relevance of adaptive learning environments [22]. Stereotype-based and combinatorial models can be developed by using artificially intelligent technologies.

The identification of an individual's need for personalisation has to be identified at the admission stage which may be divided into some of the following steps. Developing the profiles of the individuals at the time of admission to the learning facility may provide a quick overview of the previous performance of the learner, language preferences, goals of learner, location, demographics and other intrinsic characters of an individual guiding the identification and selection of parameters for identifying the need of personalization [23]. It will help to identify the factors of high influence and to decide the relevance of the learning environment not only for avoiding disruptions during the ongoing sessions but also to analyze the ability of the institute to provide personalisation. Likewise, the learners may also be exposed to different sets of tests using different mediums of learning may help the administration to identify the other personalised parameters including the level of learner's knowledge, style of learning, information seeking 
task, bandwidth and previous level of knowledge [24]. The tests and profiles, however, do not have to be used as the criteria for making authoritative decisions rather the learner may also be asked for his opinion and suggestion.

\section{B. Implementing Personalisation Parameters during Ongoing sessions}

The initially implemented personalised parameter may require consistent review for testifying their effectiveness. Therefore, an educational institution may have to adopt a series of actions and systematic steps for maintaining the effectiveness and transformation of the processes during the ongoing sessions.

The approaches implemented for implementing at the admission level have to be replicated as well. It may require an implementation of a combination of rule-based; input by the learner, rule-based; agentbased and case-based reasoning approach making it quite an applicable approach for promoting and facilitating the implementation of personalised parameters in the ongoing learning process [25].

Updating and reviewing the learner profiles periodically may be one of the most effective approaches for enabling the personalised parameter for increasing the effectiveness of the individuals. It will allow the teaching and administrative faculty of the educational institute to identify the trend of ongoing progress of the individual along with the identification for the need for further transformation and personalisation. However, these should be updated and maintained periodically for facilitating the process of the implementation personalised parameters [26]. It may be followed by the identification of the development for personal learning paths for each of the individuals, according to their level of knowledge, capacity, working memory, style of learning and other factors saving them from probable negative impacts of general educational settings. The learners should not be left dependent on personal learning paths unnecessarily which may, otherwise, result in a divergence from the standardised education system. Therefore, it should be followed by competency-based progression plans for gradually streamlining the individuals.

\section{Implementation Modeling}

The discussion highlighted that rule-based; input by learner, rule-based; agent-based and case-based reasoning approach will be used in an integrated way for developing a composite adaptive model of learning for the learners. The reason for selecting a combination of the rule-based and case-based methods for the development of adaptive learning environments is to minimise the negative impacts of either of these methods in the case of their sole application. The combinations of these approaches have already been used in computer learning and are verified for their effectiveness. However, there are always ties between rule-based reasoning (RBR) and case-based reasoning (CBR) for domination of either of them in the model and operating system [27] as shown in Figure 1.

In this case of computer learning, a balanced approach is adopted, which includes a series of categorisation of data on the basis of their nature and importance for resolving the conflicts and for increasing the pace of the reasoning processes. Categories that will be used in this model are given below.

Standalone category will include the approaches which will allow the independent functionality of CBR and RBR. In this category approaches like EFAES will be used allowing the system to cater to the issues categorically by presenting the recommendation for $\mathrm{CBR}$ and $\mathrm{RBR}$ processes separately. The flow of information in these systems will be Uni-directional in nature allowing the flow of information in a given dimension [28]. This strategy will be used for carrying out normal functions of the server for maintaining the high speed of processing. However, personalisation features required will not be neglected as well, due to compulsory sequencing depending upon the case and rules defined.

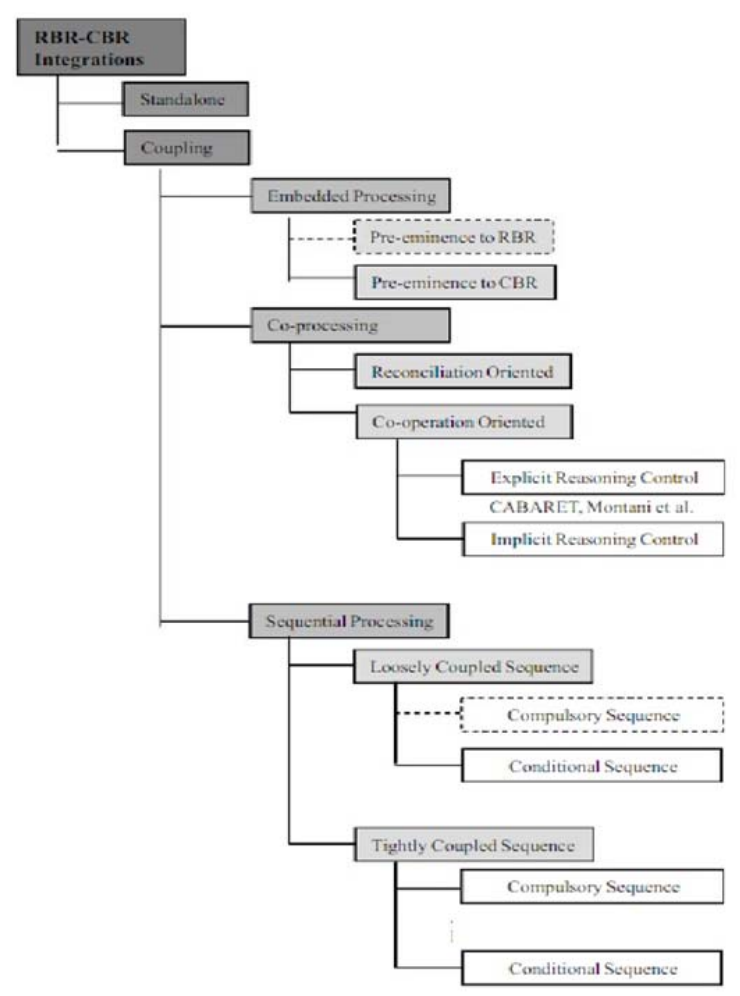

Figure 1. Implementation modelling for personalization parameters 
The model will also include a co-processing strategy for increasing the processing of the data on the basis of cases and rules in specific categories [29]. It will have a combination of conditional and compulsory sequencing for lowering the dependencies of computers on the initial computers for getting an input. However, the strategy is further divided into reconciliation oriented and co-operation oriented. The main point of consideration in this type of sequencing is that it will allow the implicit and explicit control of information comprehensively not only for increasing the speed of the processing but also for improving the quality of reasoning [30]. The flow of information, in the case of co-processing, will be bi-dimensional in nature as the components of the systems closely work together for the development of output. Likewise, embeddedprocessing will also be enabled in this model which will focus on the processing of relevant reasoning by embedding the irrelevant category helping the system develop effective and instant outputs. It is quite important in its nature that it will allow the system to develop effective outcomes at the end of the process. The third category which is included in the model is sequential processing [31]. In this type of processing, the initial information has to to pass through all of the components of the system in a predefined sequence for outputting the outcome of the project. It will allow the educational administration to segregate the learners on the basis of rules defined and cases. However, it is also important to consider that the information passing through the system does not have to be necessarily processed by all of the components, however, the information has to be passed from each of the components [32]. Therefore, the sequential processing of the model can be subdivided into a loosely coupled sequence and tightly coupled sequence. In the case of loosely coupled sequence, for example, the information like the name of the student will continue to pass through all of the components without being processed. The combination of these strategies will only allow to incorporate personalisation parameters into the category but also to maintain a high speed of processing, as well. Meanwhile, it is also considerably important that the use of information according to the cases and general settings will help the system to automatically develop the definitions of rules for increasing the effectiveness of the processes.

\section{Future Implications}

The model developed is aimed at fulfilling the needs of personalising the learner experiences on the basis of personalised parameters. The combination of RBR and CBR is used for developing the conditional and compulsory processing categories aiming that it will help to avoid the time delays and processing errors during the fulfillment of original job. However, the effectiveness of this combination is not tested in practical situation which requires empirical researches to verify the effectiveness of the design. Likewise, it should also be tested for the development of results for technicalities as well.

\section{Conclusion}

The study was aimed to identify the ways and to develop the model for the implementation of the personalised parameter for adaptive learning in the current E-learning environment. It is found that the parameters can be divided into two major categories 1) prior to the admission and 2) during the ongoing sessions. It is found that the personalised parameters that should be considered before the beginning of the course learning process include the level of learner's knowledge, goals of the leaners, preferences of the language, style of learning, information seeking task, bandwidth, location, and previous level of knowledge. On the other hand, learning needs, motivation levels, working memory capacity, intelligence, cognitive style, satisfaction, delight, and self-efficacy, the need for help, self-regulated learning, and ongoing interactions, waiting for feedback, ongoing progress, and navigation preference. Likewise, the personalised parameters identified require a combination of rule-based; input by learner, rule-based; agent-based and case-based reasoning approach for making it quite an applicable design. The design is further categorised into standalone and coupling strategies, while the coupling strategy further includes a combination of embedded, co-processing and sequential processing strategies.

\section{References}

[1] Maravanyika, M., Dlodlo, N., \& Jere, N. (2017, May). An adaptive recommender-system based framework for personalised teaching and learning on e-learning platforms. In 2017 IST-Africa Week Conference (IST-Africa) (pp. 1-9). IEEE.

[2] Nedungadi, P., \& Raman, R. (2012). A new approach to personalization: integrating e-learning and m-learning. Educational Technology Research and Development, 60(4), 659-678.

[3] Özyurt, Ö., \& Özyurt, H. (2015). Learning style based individualized adaptive e-learning environments: Content analysis of the articles published from 2005 to 2014. Computers in Human Behavior, 52, 349-358.

[4] Truong, H. M. (2016). Integrating learning styles and adaptive e-learning system: Current developments, problems and opportunities. Computers in human behavior, 55, 1185-1193. 
[5] Caballe, S., Daradoumis, T., Xhafa, F., \& Conesa, J. (2010). Enhancing knowledge management in online collaborative learning. International Journal of Software Engineering and Knowledge Engineering, 20(04), 485-497.

[6] Hwang, G. J., Sung, H. Y., Hung, C. M., Huang, I., \& Tsai, C. C. (2012). Development of a personalized educational computer game based on students' learning styles. Educational Technology Research and Development, 60(4), 623-638.

[7] Müller, C., Stahl, M., Alder, M., \& Müller, M. (2018). Learning Effectiveness and Students' Perceptions in a Flexible Learning Course. European Journal of Open, Distance and E-learning, 21(2).

[8] Premlatha, K. R., \& Geetha, T. V. (2015). Learning content design and learner adaptation for adaptive elearning environment: a survey. Artificial Intelligence Review, 44(4), 443-465.

[9] Kim, J., Lee, A., \& Ryu, H. (2013). Personality and its effects on learning performance: Design guidelines for an adaptive e-learning system based on a user model. International Journal of Industrial Ergonomics, 43(5), 450-461.

[10] Kardan, A. A., Aziz, M., \& Shahpasand, M. (2015). Adaptive systems: a content analysis on technical side for e-learning environments. Artificial intelligence review, 44(3), 365-391.

[11] Na, J. (2013). Adaptive prescribed performance control of nonlinear systems with unknown dead zone. International Journal of Adaptive Control and Signal Processing, 27(5), 426-446..

[12] Bimba, A. T., Idris, N., Al-Hunaiyyan, A., Mahmud, R. B., \& Shuib, N. L. B. M. (2017). Adaptive feedback in computer-based learning environments: a review. Adaptive Behavior, 25(5), 217-234.

[13] Al-Hunaiyyan, A., Bimba, A. T., Idris, N., \& AlSharhan, S. (2017). A cognitive knowledge-based framework for social and metacognitive support in mobile learning. Interdisciplinary Journal of Information, Knowledge \& Management, 12.

[14] Vandewaetere, M., Desmet, P., \& Clarebout, G. (2011). The contribution of learner characteristics in the development of computer-based adaptive learning environments. Computers in Human Behavior, 27(1), 118-130.

[15] Bousbia, N., \& Belamri, I. (2014). Which contribution does EDM provide to computer-based learning environments? In Educational data mining (pp. 3-28). Springer, Cham.

[16] Phobun, P., \& Vicheanpanya, J. (2010). Adaptive intelligent tutoring systems for e-learning systems. Procedia-Social and Behavioral Sciences, 2(2), 4064-4069.

[17] Klašnja-Milićević, A., Vesin, B., Ivanović, M., \& Budimac, Z. (2011). E-Learning personalization based on hybrid recommendation strategy and learning style identification. Computers \& Education, 56(3), 885-899.
[18] Tompkins, E. K. (2016). Application of cognitive apprenticeship model (CA) to library instruction. College \& Undergraduate Libraries, 23(1), 1-15.

[19] Tompkins, E. K. (2016). Application of cognitive apprenticeship model (CA) to library instruction. College \& Undergraduate Libraries, 23(1), 1-15.

[20] Athanasiadis, C., Hortal, E., Koutsoukos, D., Lens, C. Z., \& Asteriadis, S. (2017, April). Personalized, Affect and Performance-driven Computer-based Learning. In CSEDU (1) (pp. 132-139).

[21] Groat, A., \& Musson, T. (1995). Learning styles: individualizing computer-based learning environments. ALT-J, 3(2), 53-62.

[22] Jeong, H. Y., Choi, C. R., \& Song, Y. J. (2012). Personalized Learning Course Planner with Elearning DSS using user profile. Expert Systems with Applications, 39(3), 2567-2577.

[23] Khandelwal, K., \& Sharma, D. P. (2013). Hybrid Reasoning Model for Strengthening the problem solving capability of Expert Systems. Int. J. Adv. Comput. Sci. Appl.(IJACSA), 4.

[24] Tung, Y. H., Tseng, S. S., Weng, J. F., Lee, T. P., Liao, A. Y., \& Tsai, W. N. (2010). A rule-based CBR approach for expert finding and problem diagnosis. Expert Systems with Applications, 37(3), 2427-2438.

[25] Prentzas, J., \& Hatzilygeroudis, I. (2011). Casebased reasoning integrations: Approaches and applications. Case-based reasoning: processes, suitability and applications, 1-28.

[26] Avdeenko, T. V., \& Makarova, E. S. (2018). Knowledge representation model based on casebased reasoning and the domain ontology: Application to the IT consultation. IFACPapersOnLine, 51(11), 1218-1223.

[27] Zhang, S., \& Wu, X. (2011). Fundamentals of association rules in data mining and knowledge discovery. Wiley Interdisciplinary Reviews: Data Mining and Knowledge Discovery, 1(2), 97-116.

[28] Peng, G., Chen, G., Wu, C., Xin, H., \& Jiang, Y. (2011). Applying RBR and CBR to develop a VR based integrated system for machining fixture design. Expert Systems with Applications, 38(1), 2638.

[29] Khamparia, A., \& Pandey, B. (2015). Knowledge and intelligent computing methods in elearning. International Journal of Technology Enhanced Learning, 7(3), 221-242.

[30] Salehi, M. (2013). Application of implicit and explicit attribute based collaborative filtering and BIDE for learning resource recommendation. Data \& Knowledge Engineering, 87, 130-145.

[31] Lim, T. P., Husain, W., \& Zakaria, N. (2013). Recommender system for personalised wellness therapy. International Journal of Advanced Computer Science and Applications, 4.

[32] Goh, Y. M., \& Guo, B. H. (2018). FPSWizard: A web-based CBR-RBR system for supporting the design of active fall protection systems. Automation in Construction, 85, 40-50. 